\title{
O Novo Estado da Arte dos Estudos em Performance
}

\author{
Ian Pace | City University of London | Inglaterra \\ Vitória Louveira | William Teixeira \\ Universidade Federal de Mato Grosso do Sul | Brasil
}

\begin{abstract}
Resumo: A performance-como-pesquisa e a performance baseada em pesquisa são alvos de críticas constantes na academia. Autores como Clarke, Cook e Daniel Leech-Wilkinson integram um grupo muito proeminente de pesquisadores que abordam esse assunto. Cook se destaca com o livro Beyond the Score: Music as Performance (livro que será analisado durante este texto), no qual realiza críticas duras e, por vezes, precipitadas, à performance da música de concerto, especialmente da que ele chama de 'performance modernista'. Por meio dele é possível conhecer outros autores de seu grupo que apoiam ideias similares. Acontece que Cook, com seu tom, parece esperar que seus leitores partam de conhecimentos tácitos acerca da realidade atual da performance musical e dos estudos em performance. A análise feita aqui, principalmente deste livro, vem para estabelecer um contraponto e para tentar conter algumas de suas ideias depreciativas sobre a pesquisa em performance, a performance musical e outros campos que permeiam a ramificação dos estudos em performance. [resumo elaborado pelos tradutores]
\end{abstract}

Palavras-chave: Performance musical, Estudos em performance, Pesquisa em performance

\begin{abstract}
Performance-as-research and research-based performance are the target of constant criticism in the scholarship, Authors such as Clarke, Cook and Daniel Leech-Wilkinson are part of a very prominent group of researchers that address this subject. Cook stands out with the book Beyond the Score: Music as Performance (main book that will be analysed during the text), in which he conducts harsh and, at times, hasty criticisms on the performance of Western art music, especially of something he calls 'Modernist' performance. Through his work, it is possible to reach other authors of his group who support similar ideas. It turns out that Cook, with his tone, seems to expect his readers to start from some tacit knowledge about the current reality of music performance and performance studies. The analysis made here, mainly of this book, comes to balance the discussion and to try to contain some of his derogatory ideas about performance research, musical performance and other fields that permeate the branch of performance studies. [abstract provided by the translators]
\end{abstract}

Keywords: Musical Performance, Performance Studies, Research in Performance 
$\mathrm{E}$ m um ensaio publicado em $2004^{1}$, John Rink, caracteriza o campo dos 'Estudos em Performance' na música em 'três domínios sobrepostos': a performance histórica, a psicologia da performance, e a análise e performance. Dentro destas categorias, ele encontra uma série de problemáticas específicas com as quais trabalha, respectivamente: a música de concerto ocidental, o repertório para piano solo e o estudo do tempo e da dinâmica musicais. Destes, a performance histórica (HIP - Historically Informed Performance) $)^{2}$ é a mais antiga, atribuindo-se seu início ao trabalho de François-Joseph Fétis em 1830, ganhando proeminência mais tarde naquele século. $\mathrm{Na}$ época do ensaio de Rink, o campo já abarcava também o estudo de gravações históricas, constituído a partir do trabalho pioneiro de Robert Philip, a 'fonomusicologia'3. (Eu prefiro ver gravaçôes e vídeos mais como fontes de pesquisa para o estudo da performance musical, limitadas a algumas aplicabilidades no repertório do século XIX, e praticamente nenhuma para períodos anteriores). O estudo da performance histórica atualmente inclui instrumentos históricos, técnicas, estilos de performance em tempos e lugares específicos, autorreflexão sobre metodologias e consideraçốes estéticas mais gerais. ${ }^{4}$ A psicologia da performance surgiu no início dos anos 1980, através dos importantes trabalhos de John Sloboda e Eric Clarke. A Análise e Performance veio à tona nos anos 1990, mediante um debate seguido pela publicação por Wallace Berry de Musical Structure and Performance [Estrutura musical e performance] em $1989^{5}$, sendo este campo notável por grandes contribuiçóes de Rink, Jonathan Dunsby, e Nicholas Cook. ${ }^{6}$

\footnotetext{
${ }^{1}$ John Rink. The State of Play in Performance Studies', In: Jane W. Davidson (ed.). The Music Practitioner: Research for the Music Performer, Teacher and Listen (Aldershot, 2004), 37 - 52.

${ }^{2}$ Performance historicamente informada é a tradução de Historically Informed Performance (HIP), o que justifica o uso da sigla original.

${ }^{3}$ Robert Philip. Early Recordings and Musical Style: 1900-1950 (Cambridge, 1992); Stephen Cottrell. 'The Rise and Rise of Phonomusicology', em Amanda Bayley (ed.). Recorded Music: Performance, Culture and Technology (Cambridge, 2010), 15 - 36.

${ }^{4}$ Como fica óbvio em volumes como Nicholas Kenyon (ed.). Authenticity and Early Music (Oxford, 1988); Richard Taruskin. Text and Act: Essays on Music and Performance (Oxford, 1995); e Peter Walls. History, Imagination, and the Performance of Music (Woodbridge and Rochester, NY, 2003).

${ }^{5}$ Wallace Berry. Musical Structure and Performance (New Haven, 1989).

${ }^{6}$ Jonathan Dunsby. Performing Music: Shared Concerns (Oxford, 1995); John Rink (ed.), The Practice of Performance: Studies in Musical Interpretation (Cambridge, 1995); e Nicholas Cook, Analyzing Musical Multimedia (Oxford, 1998), 'Analysing Performance and Performing Analysis', em Cook e Mark Everist (eds.), Rethinking Music (Oxford, 1999), 239 - 61; e 'Words about Music, or Analysis Versus Performance', em Cook, Peter Johnson e Hans Zender, Theory into Practice: Composition, Performance and the Listening Experience (Leuven, 1999), 9 - 52.
} 
Esse assunto tem se expandido em subdisciplinas desde o trabalho de Rink, e eu gostaria de identificar mais um importante domínio já estabelecido naquela época - a reflexão crítica, filosófica e teológica sobre a performance, que por vezes baseia-se em pesquisas acadêmicas nas áreas do teatro, performance e performatividade ${ }^{7}$. A esses campos, eu gostaria de acrescentar pelo menos outros oito que se estruturaram posteriormente, alguns se sobrepondo às categorias mencionadas por Rink. São eles: a performance-como-pesquisa e a pesquisa baseada em performance, geralmente realizadas por performers, requerendo algum elemento prático; o estudo da performance da música contemporânea, incluindo técnicas e práticas, sendo este um campo pouco desenvolvido em termos de metodologia crítica; os estudos etnográficos em performance musical e performers; a história cultural e estudo das performances considerando performances e grupos particulares, relacionando suas características musicais à um contexto cultural e social mais amplo; o estudos das performances tradicionais, um campo que incorpora alguns dos melhores trabalhos dos estudos da música popular e da etnomusicologia; estudos detalhados sobre performers e grupos específicos, investigando intensamente o trabalho musical de performers individuais ou grupos, como bandas, orquestras, coros, etc. (uma tradição que na maior partes dos contextos ocidentais tem sido conduzida majoritariamente por amadores); a pedagogia da performance histórica e comparada; e finalmente o estudo da teatralidade da performance.

No Reino Unido, pode-se identificar três grupos principais de acadêmicos trabalhando em performance. O primeiro, focando mais especificamente na Performance Historicamente Informada, está centrado na Universidade de Leeds e reúne muitos artistas ativos, incluindo Clive Brown, Peter Holman, David Milsom, George Kennaway e Neal Peres da Costa. Um segundo grupo é mais focado nos instrumentos musicais e inclui o trabalho de Colin Lawson e Robin Stowell. O terceiro e, hoje, o mais poderoso e influente, abrange várias universidades e centros em torno de quatro estudiosos: Rink, Clarke, Cook e Daniel Leech-Wilkinson. Seu esforço coletivo mais notável foi o estabelecimento do CHARM, o AHRC Centro de Pesquisa para a História e a Análise da Música Gravada, em 2004, ${ }^{8}$ estando eles envolvidos no projeto do software Sonic

\footnotetext{
${ }^{7}$ Como Peter Kivy. Authenticities: Philosophical Reflections on Musical Performance (Ithaca and London, 1995); ou Stephen Davies. Musical Works and Performances: A Philosophical Exploration (Oxford, 2001).

${ }^{8} \mathrm{O}$ site do CHARM é http://www.charm.rhul.ac.uk/index.html (acessado em 15 de novembro de 2015). Um texto chave (também altamente partidário e polêmico) associado a esse grupo de estudiosos é Nicholas Cook, Eric Clarke,
} 
Visualiser, usado em vários projetos do CHARM. Coletivamente, esses quatro estudiosos trabalharam nos domínios descritos acima, mas a ênfase de seu trabalho está distante da pesquisa em Performance Historicamente Informada dos outros dois grupos (a não ser o trabalho de Rink sobre Chopin e de Leech-Wilkinson sobre música medieval). Cook se destacou nos estudos britânicos sobre a performance musical. Além das pesquisas sobre performance da música antiga e o trabalho do grupo da Universidade de Leeds, existem poucas publicaçóes no Reino Unido ou projetos de pesquisa financiados que não estejam sob os auspícios ou a influência desse grande grupo.

Os escritos mais antigos de Cook sobre a performance musical estavam mais ligados com os domínios da HIP com a análise e performance e a reflexão crítica e filosófica (apesar de reconhecer e basear-se em outras abordagens). O seu livro Beyond the Score: Music as Performance [Além da partitura: a música como performance], ainda seu trabalho mais consistente sobre performance, continua nessa direção. ${ }^{9}$ Não há dúvida de que este é um trabalho de enorme erudição e complexidade e que, como tal, constitui uma significativa contribuição à área. No entanto, seu tom retórico com o uso de argumentos de espantalho, seu posicionamento populista e, às vezes, um estilo de escrita muito formal, tornam esse trabalho muito problemático em termos acadêmicos. Digo isso com relutância, pois fiquei impressionado com alguns dos trabalhos anteriores de Cook sobre o assunto (e não menos importante, seu livro sobre Heinrich Schenker), um pouco do qual está incorporado neste livro novo.

O objetivo explícito do livro é corrigir as hierarquias da música ocidental - especialmente com respeito ao período da prática comum - que ele diz favorecer a compositores e construções de "obras" musicais ao invés de performers e performances. Que a performance deva ser abordada de forma mais central e regular dentro da musicologia, isso é uma questão importante, que certamente seria contestada apenas por tradicionalistas obstinados, compositores de estúdio ou outros compositores que não desejam perder seu status privilegiado na academia ou na música contemporânea. Mas Cook parece ir longe demais: em seus escritos percebo uma valorização

Daniel Leech-Wilkinson e John Rink (orgs.), The Cambridge Companion to Recorded Music (Cambridge, 2009); o outro é a monografia online de Leech-Wilkinson, The Changing Sound of Music: Approaches to Studying Recorded Musical Performances (Londres, 2009), em http://www.charm.rhul.ac.uk/studies/chapters/intro.html (acessado em 10 de novembro de 2015), um trabalho com ideias interessantes, mas também com afirmações históricas bastante abrangentes, com base em poucas evidências.

${ }^{9}$ Nicholas Cook. Beyond the Score: Music as Performance. pp. xvii 458. (Oxford University Press, Nova York e Oxford, 2013) 
implícita do ato sobre o texto e - em comum a muitos novos musicólogos - uma visão depreciativa da música escrita, de maneira que às vezes aponta para um anti-alfabetização generalizada.

Cook baseia-se em uma grande e impressionante variedade de bibliografias secundárias, mas o grau de envolvimento crítico com essas fontes é seletivo. Escritos que apoiam posiçóes antimodernistas e anti-Performance Histórica geralmente escapam das críticas, assim como outros que apoiam membros do CHARM. A bibliografia é principalmente monolíngue, com apenas sete entradas em idioma estrangeiro em uma lista de 612 textos. Os escritos de Schenker e Adorno sobre performance, existentes em tradução para o inglês, são considerados, mas não os de Rudolf Kolisch, ou da poderosa coleção de ensaios sobre a performance da segunda escola de Viena editada por Markus Grassl e Reinhard Kapp. Não há nada em relação ao extenso debate sobre Auffuhrungspraxis, Authentizitat and Werktreue que aconteceu em alemão a partir da década de 1950 (com antecedentes da década de 1920), antes das intervenções de Leech-Wilkinson, Taruskin e outros, que essencialmente não examinaram nenhuma questão que esses estudiosos anteriores já não tivessem debatido exaustivamente. ${ }^{10}$

Em outros lugares, Cook declarou sua antipatia pela defesa musicológica, desconsiderando-a por seus "musicólogos ou teóricos emitindo seus ingressos para o hall da fama do cânone" 11 , mas ele faz o mesmo com relação a outros estudiosos, muitos dos quais terão suas reputações reforçadas. De fato, musicólogos aparecem com mais proeminência em seu trabalho do que compositores ou intérpretes: há mais menções de Eric Clarke, Mine Dogflnatan-Dack, Bruno Repp e Neil Todd do que de Stravinsky, Boulez, Nadia Boulanger e Nikolaus Harnoncourt. Alguns leitores internacionais podem considerar suas escolhas de músicos provinciais (ou mesmo anglo cêntricas). Um trecho significativo do livro é dedicado ao que seria justo se descrever como uma peça de piano relativamente menor de Bryn Harrison e sua performance não muito relevante por Philip Thomas,

\footnotetext{
${ }^{10}$ Uma variedade deles, como os escritos de Harald Heckmann, Wilhelm Fischer, Walter Wiora e Georg von Dadelsen, são citados por Dorottya Fabian em seu artigo "The Meaning of Authenticity and the Early Music Movement: A Historical Review', International Review of the Aesthetics and Sociology of Music, 32/2 (dezembro de 2001), 67-153 [Revista Internacional de Estética e Sociologia da Música]. No fim de um texto importante não mencionado por Fabian, Gotthold Frotscher, Auffübrungspraxis alter Musik (Wilhelmshaven e Amsterdam, 1963), 9- 168, existe uma consciência clara das autoconstruções de abordagens 'subjetivas' e 'objetivas' por formadores de música histórica, e Frotscher conclui que ambos envolvem visões simplistas e despersonalizadas de Bach, um posição mais sutil do que a argumentada por Taruskin mais de duas décadas depois.

${ }^{11}$ Cook, 'Writing on Music or Axes to Grind: Road Rage and Music Community' Musical Education Research, 5/3 (Nov. 2003), 61- $249 \mathrm{em} 260$.
} 
entretanto John Cage é mencionado apenas de passagem e David Tudor, Aloys Kontrasky ou Siegfried Palm não são nem mencionados.

Os capítulos iniciais do volume tratam de modelos e métodos existentes. Os próximos quatro, em sua essência, são fundamentados em análises de documentos sônicos: um piano-roll do Impromptu de Schubert interpretado por Eugen d'Albert, juntamente com uma análise da peça por Schenker (cap. 3), uma série de gravaçóes da Sonata para piano K. 332 de Mozart e o Rondo alla turca, em particular uma gravação de Carl Reinecke, para considerar uma performance retórica (cap. 4) e, em seguida, dois capítulos com base no trabalho mais amplo realizado pelo CHARM sobre Mazurkas de Chopin no contexto da análise de estilo e do "fraseado" ${ }^{2}$ O Capítulo 7 considera questôes sobre obras e performances e é seguido por um problemático capítulo sobre 'Scripts sociais', tratando das interações entre performers; é esse o local onde Cook mais trata da música nova. Os últimos quatro capítulos pesam menos na abordagem: os capítulos 9 e 10 analisam o papel do corpo na performance, mas sem relacionar isso ao som de maneira fundamentada. Os Capítulos 11 e 12 tematizam a relação entre a performance e a gravação, baseando-se fortemente no trabalho de Philip Auslander, e, no mais, aderindo a uma visão essencialmente populista e comercial da produção musical moderna. Cook praticamente não menciona a composição em estúdio ou por softwares (cada vez mais importantes na produção musical comercial), o que teria colocado em perspectiva seu material sobre edição e sobre o trabalho de Jon Culshaw e Glenn Gould, além de levantar questóes sobre os aspectos fundamentais da ontologia da performance. Também está ausente qualquer consideração sobre o papel central de estações de rádio em apoiar e possibilitar uma grande variedade de performances no século $\mathrm{XX}$, todas as quais seriam gravados para transmissão posterior e assim, atingiriam permanência. Tal consideração teria melhor detalhado as diferenças entre abordagens para concertos ao vivo e para gravaçóes.

O foco detalhado em três diferentes peças para piano certamente não é acidental. Por causa da relativa clareza do ataque das notas, Cook é capaz de quantificar os parâmetros que parecem importantes - principalmente tempo e ritmo (sem tratar da condução de vozes, o uso de legato e do pedal), para o qual ele pode usar o software para produzir gráficos. Estas questóes são as vezes - em sua análise de d'Albert tocando Schubert - consideradas isoladamente, em vez de serem tratadas em

\footnotetext{
${ }^{12}$ Consulte "'Style, Performance, and Meaning in Chopin's, em http://www.charm.rhul.ac.uk/projects/p2_3.html (acesso em 18 de novembro de 2015).
} 
sua relação com outros parâmetros, como a harmonia. Em performances com instrumentos de cordas ou sopros, falar da condução de vozes sem considerar detalhadamente timbre, arcadas, vibrato e respirações seria uma falta mais óbvia. ${ }^{13}$ Cook é crítico de métodos mais antigos de escuta atenta, usando métodos mais ad hoc, mas sem reconhecer esses tipos de limitações. Essa atitude em relação à escuta atenta contrasta com sua apropriação acrítica de citações anedóticas e jornalísticas de estudos etnográficos. ${ }^{14}$

Cook escreveu repetidamente sobre problematizar o conceito de obra e suas reflexốes estão entre as mais rigorosas. Aqui ele usa exemplos familiares: padrões de jazz e as Sonatas para Violino Op. 5 de Corelli. Ele também salienta que nenhum músico pode simplesmente executar as instruções muitas vezes ambíguas da maneira como o computador reproduz um arquivo MIDI (p. 235). Mas o computador não está livre da agência humana também. Todo software relevante envolve meios de conversão de dados em sons que refletem a estética notacional do programador, ou seja, mesmo a partir de um software é possível perceber a estética musical do programador. O modelo de Cook é sustentado pela concepção de uma performance “em branco" (meu termo), sendo a criatividade um “extra”. Mas eu diria que esse tipo de performance é resultado apenas de uma das muitas maneiras de se ler a notação (mesmo quando lida indiretamente pelo software) e não é mais neutra ou não estilizada do que, digamos, a prosa de Hemingway ou Camus. Cook escreve que "artistas adicionam conteúdo sonoro específico” à moldura criada pelos compositores, uma metáfora um pouco estranha, mas depois ele parece se contradizer dizendo que "performances não simplesmente reproduzem as partituras, mas também não simplesmente as preenchem” (p. 236). Ele paira sobre a ideia de que "os artistas apagam a partitura" e isso implica entender a importância da improvisação, concluindo, finalmente, que "no tempo real da performance tudo está sempre sendo feito pela primeira vez” (ibid.). Mas esse modelo é negativo em relação à música erudita (ou notada). Eu prefiro ver a notação como um meio para perceber a imaginação criativa

\footnotetext{
${ }^{13}$ Veja as críticas de Cook à suposta negligência de Dahlhaus em relação às qualidades timbrais, texturais e performativas da música popular em Writing on Music or Axes to Grind', 259.

${ }^{14}$ Por exemplo, os músicos pareciam responder um ao outro em desafio que ampliaram sua criatividade conjunta, para Frederick Seddon e Michele Biasutti, 'A Comparison of Modes of Communication between Members of a String Quartet and a Jazz Quartet', [Uma comparação de modos de comunicação entre Membros de um Quarteto de Cordas e um Quarteto de Jazz ] Psychology of Music, 37 (2009), 395 - 415 em 407, citado de Cook, p. 237; ou or 'I think you have to let your own voice shine. I think a good conductor does that', [Acho que você precisa deixar sua própria voz brilhar. Eu acho que um bom maestro faz isso], em Cottrell, Professional Music-Making in London, 108, citado por Cook, p. 269
} 
dos artistas diante das orientaçóes disponíveis, e não como um obstáculo. Posso concordar com Cook que "não existe nenhuma razão para privilegiar o próprio conhecimento de Schubert sobre o que pode ser criado a partir do que ele escreveu", mas sua afirmação de que "este é um pequeno exemplo do que significa pensar na música como performance” (p. 67) é superficial. De várias maneiras, a interpretação ainda está em jogo com a partitura e as possibilidades não são ilimitadas (se d'Albert substituísse todos os acordes por clusters, digamos, poucos poderiam negar que isso estenderia a concepção do que significa tocar essa partitura de Schubert).

Embora existam referências frequentes à improvisação, há apenas uma seção muito curta sobre improvisação livre (pp. 226-7). Cook estabelece um modelo normativo para esse campo com base em três citações (duas de musicólogos, uma de um músico de jazz e nenhuma de improvisadores livres) sobre a improvisação estar sempre em torno de 'alguma coisa'. É verdade que a improvisação nunca pode ser totalmente "livre" (mesmo que tudo o que se saiba previamente sejam os instrumentos disponíveis e a duração máxima) e, em alguns casos, pode-se até se falar de um texto que é comunicado oralmente entre músicos, em vez de estarem na forma escrita, mas o desenho de conclusóes muito amplas de Cook serve para marginalizar um importante e diversificado campo de prática.

$\mathrm{Na}$ introdução, Cook afirma que seu livro "não pretende ser um ataque à performance moderna” (p. 3), mas talvez seja isso sim. Uma vaga concepção de "modernismo" (algumas vezes mencionado como sinônimo de 'estruturalismo', um problema ao qual voltarei) é um "outro" sempre presente, polarização sem a qual muitos dos argumentos perderiam grande parte de sua força retórica. ${ }^{15}$ No entanto, o termo nunca é definido de tal maneira que possa ser aplicado a um corpo significativo de trabalhos. Cook parece assumir que seu leitor compartilhará sua visão negativa de algo chamado de "modernista" e, portanto, não exigirá explicação adicional, nem desejar qualquer nuance. Ele repete sem escrutínio o argumento circular de Richard Taruskin falando que uma "performance musical verdadeiramente modernista" apresenta a obra como se

\footnotetext{
${ }^{15}$ O livro de Cook é tão partidário a esse respeito quanto de Bruce Haynes, The End of Early Music: A Period Performer's History of Music (Nova York e Oxford, 2007) [O fim da música antiga] (que Cook surpreendentemente nunca cita). Haynes postula três grandes estilos de performance do século XX, "Romantico", que durou até a Primeira Guerra Mundial, "Moderno",começando neste ponto e continuando até a década de 1960 e, posteriormente, "retórico". Ele deixa claro que considera 'o modelo o espírito modernista foi uma desgraça para a música da última parte do século $\mathrm{XX}^{\prime}$ (p. 32).
} 
composta ou executada por Stravinsky (p. 219), circular porque a definição de Taruskin de “modernista” já é essencialmente de um Stravinskiano. Cook afirma que "a cultura da performance da Música de Concerto Ocidental é, sem dúvida, mais pluralista agora do que há algumas décadas atrás” e que "essa ampliação que acolhe outros horizontes musicais se reflete no relaxamento do controle do modernismo nas salas de concertos” (p. 131), mas essa afirmação exige que se compartilhe sua concepção esmagadoramente negativa e rígida de "modernismo" (e, portanto, a concepção pluralista de "pós-modernismo").

Ele também escreve com desaprovação sobre como os "modernistas supostamente se portavam seletivamente diante do que chamamos agora de pré-moderno" (p. 130), mas sua visão do modernismo é igualmente seletiva. Ele chama a performance modernista de "o produto de uma cultura em que é a exceção para intérpretes também serem compositores” (p. 127), o que excluiria Busoni, Hindemith, Artur Schnabel, Boulez, René Leibowitz, Bruno Maderna, Gyorgy Kurtág e outros. Ou "a estética de Hanslick se tornou som", porque, de acordo com Cook, nos termos de Hanslick “a expressão é algo colocado acima da estrutura” (p. 127), um argumento que poderia ser diferente se os muitos escritos críticos de Hanslick fossem investigados bem como seu tratado inicial. Em diferentes épocas, Landowska, Schenker, Schnabel, Schoenberg, Stravinsky, Hindemith, Furtwangler, Boulez e Alicia de Larrocha (embora não necessariamente Adorno) estão associados à performance modernista. Schenker, nos é dito, "lançou as bases” da "teoria musical modernista”, que "em conjunto com a estética modernista e a performance modernista" transformaram os clássicos “em objetos musicais perfeitos, perfeitamente reproduzidos” (p. 134), uma afirmação extravagante que precisa de mais evidências (acho difícil reconhecer isso em alguns dos nomes citados acima desta descrição). Os artistas mais proeminentes da música nova são amplamente omitidos, mesmo aqueles também associados ao repertório da era da prática comum. Não há nada sobre Leibowitz, Hans Rosbaud ou Maderna e apenas uma breve menção a Hermann Scherchen; Claudio Abbado e Maurizio Pollini são mencionados apenas de passagem, e Pierre Boulez é abordado por meio de suas falas e não por suas performances. ${ }^{16}$

\footnotetext{
${ }^{16} \mathrm{Eu}$ devo declarar interesse, pois Cook cita brevemente meu próprio artigo sobre notação e performance contemporânea 'Notation, Time and the Performer's Relationship to the Score in Contemporary Music', em Darla Crispin (ed.), Unfolding Time: Studies in Temporality in Twentieth-Century Music (Leuven, (Leuven, 2009), 151 - 92), como o caso mais explícito em 'performance equivalent of Frankfurt-School critical theory', ao lado dos escritos de Roger Heaton e Frank Cox (p. 281) Pessoalmente, estou muito satisfeito com essa visão.
} 
Um estilo de comitê (Stilkommission), foi criado pela Academia de Música e Artes Cênicas de Viena para encontrar o estilo de tocar que precedeu as distorçóes percebidas em Bach pelas mãos de Liszt e Busoni e em Chopin por artistas posteriores (pp. 27, 128). ${ }^{17}$ Uma pequena citação de Robert Hill, resumindo a "limpeza” da performance pela comissão é citado por Cook com horror aparente (p. 27), apesar do fato de que a comissão foi inundada por outras preocupaçóes institucionais e nunca realmente funcionou. ${ }^{18} \mathrm{~A}$ linguagem carregada de Cook corresponde facilmente, e até supera, ao daqueles por trás da Stilkommission" ${ }^{19}$ e faz parte de seu ataque mais amplo "ao conflito entre performances clássicas e modernistas” (p. 128). Mas há uma crença de que nem todos os desenvolvimentos recentes representaram um progresso desqualificado, o que de maneira alguma equivale a uma evocação total de um passado idealizado. Edições pesadamente alteradas de Bach por Busoni, ou de Beethoven por Bulow, são documentos fascinantes por si só, mas por causa de sua licença criativa e seus limites nem sempre são claros, não gostaríamos que fossem tratadas como cópias.

Em seu influente estudo de 1992 sobre gravações antigas, Robert Philip apresentou uma diminuição da diversidade de interpretações e (correspondentemente) um crescimento do literalismo ao longo do século XX, uma visão refletida nos escritos de Richard Taruskin, e que foi ressaltada em muitos trabalhos de pesquisadores do CHARM. A crítica mais promissora sobre esse assunto, em inglês, é o trabalho de Dorottya Fabian, que investigou documentos e fonogramas, encontrando evidências de literalismo nas performances de Bach e alguns outros compositores bem antes do século XX. Ela também argumentou, com base nessas fontes que, de certa forma, a diversidade aumentou em vez de ter diminuído ao longo do século XX, e que a realidade de muitos praticantes da Performance Historicamente Informada está frequentemente em desacordo com seus pronunciamentos verbais ou com os de outros associados a eles. ${ }^{20}$

\footnotetext{
17 Depois renomeada como Arbeitsgemeinschaft fur musikalische Werkpraxis. Veja Robert Hill, "Overcoming Romanticism” sobre a modernização das práticas de performance do século XX ', em Bryan Gilliam (ed.), Music and Performance during the Weimar Republic (Cambridge, 1994), 37 - 58 em 46 - 7.

${ }^{18}$ Harmut Krones, '175 Jahre Auffuhrungspraxis Alter Musik in Wien', em Krones (ed.), Alte Musik und Musikpadagogik (Viena, Colônia e Weimar, 1997), 15-22 em 20- 1.

${ }^{19}$ É notável quão diferente é o modo como Cook cita uma alegação de que aparentemente "interpretações que se afastam muito da música original não foram permitidas” no Concurso Internacional Chopin (p. 174).

${ }^{20}$ Veja Dorottya Fabian, 'The Meaning of Authenticity and the Early Music Movement". Movement - A Historical Review', International Review of the Aesthetics and Sociology of Music, [Uma revisão histórica, Revista Internacional de
} 
Foi possível para Philip e outros que o seguiram, como Timothy Day, David Milsom, Will Crutchfield e Neal Peres da Costa, ${ }^{21}$ se envolverem minuciosamente com a amplitude de material gravado do período investigado (embora isso seja minúsculo em comparação com a quantidade de performances ao vivo durante esse período, um fator que poderia modificar conclusões muito amplas). No entanto, o grande número de gravaçóes feitas após 1945, coloca-os fora do alcance de pesquisadores independentes. Fabian olhou para uma ampla gama de gravações de algumas obras selecionadas de Bach, enquanto Bruce Haynes e Leech-Wilkinson compararam as primeiras gravações com uma pequena e não necessariamente representativa amostra daquelas realizadas depois de $1945,{ }^{22}$ mas ainda resta muito trabalho a ser realizado nas subseçóes deste corpo posterior de evidências registradas, de modo que conclusões mais amplas possa ser tiradas com confiabilidade acadêmica.

Fabian, no entanto, demonstrou que as conclusóes de Philip, Taruskin e outros eram problemáticas. Da mesma forma, Cook observa uma crescente divergência no tempo nas gravaçóes de Schubert após 1945 (pp. 82-3). Mas ele defende uma ideologia homogênea do pós-guerra em sua investigação sobre "fraseados" - ficando mais rápidos e com mais intensidade no auge de uma frase e mais lento e suave quando estiver terminando essa frase - teorizadas por Neil Todd. Em uma análise de trinta e três gravaçôes da Mazurka Op. 63, no 3, de Chopin, feitas entre 1923 e 2003, Cook considera essa prática comum nas gravaçôes anteriores a 1945, em estado de transição nas gravações de Andor Foëdes (1945) e Vladimir Horowitz (1949), e então no auge com Heinrich Neuhaus (1953), continuando em um pequeno número de gravações subsequentes. Cook mesmo observa inconsistências em uma amostra paralela de sete gravaçóes do Op. 17, No. 4, tocadas por

Estética e Sociologia da Música], 32/2 (dezembro de 2001), 153 -67; Bach Performance Practice 1945-1975: A Review of Sound Recordings and Literature (Aldershot, 2003); isso é; 2003); 'Is Diversity in Musical Performance truly in Decline?: The Evidence of Sound Recordings', [A diversidade da performance musical está realmente em declínio?: A evidência das gravaçôes sonoras], Context: A Journal of Music Research, 31 (2006), 165 - 80. Cook cita apenas o último deles.

${ }^{21}$ Timothy Day, A Century of Recorded Music: Listening to Musical History (New Haven, 2000); David Milsom, Theory and Practice in Late Nineteenth-Century Violin Performance (Aldershot, 2003); Will Crutchfield, Performance Desempenho vocal no Século XIX ', em Colin Lawson e Robin Stowell (eds.), The Cambridge History of Musical Performance (Cambridge, 2012), 611-42; Neal Peres Da Costa, off the record: Off the Record: Performing Practices in Romantic Piano Playing (Nova York e Oxford, 2012).

${ }^{22}$ Em Haynes, The End of Early Music, e Leech-Wilkinson, The Changing Sound of Music, e 'Recordings and Histories of Performance Style', [Gravaçóes e histórias do estilo de apresentação] em The Cambridge Companion to Recorded Music, 246 - 62. 
apenas três pianistas, afirmando que esse fraseado era um "fenômeno do período pós-guerra" e um modelo "para alguns aspectos da expressão musical durante a segunda metade do século XX”" (p. 205, em itálico por Cook), em particular na Rússia. Mais tarde, ele recua momentaneamente, reconhecendo que os resultados para as duas Mazurkas podem não ser replicados em outros lugares, para não falar da performance do piano como representativa para outros meios instrumentais e vocais (p. 209), mas isso não inibe sua ação especulativa que relaciona essa abordagem do fraseado em termos de um culto estético da simplicidade através de uma leitura parcial da obra de Isadora Duncan, Coco Chanel, Osbert Lan- Le Corbusier, Adolf Loos e Buckminster Fuller, levando-o à frases importantes como "a nova simplicidade do fraseado no pós-guerra" (p. 217).

Cook afirma: "meu objetivo não foi apresentar uma visão generalizadas dos músicos gravados antigamente, mas focar em alguns daqueles que, pela diferença das práticas atuais, incorporam mais claramente ao que o estudo da performance histórica deveria se adequar” (p. 131). Mas, para que esse estudo seja genuinamente "histórico", ele precisa incorporar uma visão geral equilibrada. Seu retrato da Performance Historicamente Informada a remove - erroneamente na minha opinião da história da performance da música antiga e da aplicação frequente de métodos desenvolvidos para repertórios posteriores. Ele escreve que a 'forma moderna' da Performance Historicamente Informada começou no final da década de 1960 (o motivo da escolha dessa data não é claro) e foi "uma reação contra as convenções estabelecidas na performance do pós-guerra” (p. 26), uma declaração que ecoa a polêmica de Leech-Wilkinson. ${ }^{23}$ Nenhum exemplo é dado da "retórica agressivamente autenticista que marcou os primeiros anos de Performance Historicamente Informada", nem da alegação (contestada por Fabian), de que "todo o renascimento da performance da música antiga foi construído" em torno de uma alegação de que "certas práticas de performance eram autênticas enquanto outras não eram" (p. 13). Cook reconhece que "a Performance Historicamente Informada tem raízes históricas antigas” (ibid.), nomeando apenas o trabalho de Dolmetsch, mas não explicando como (ou de fato se) essa "forma moderna" difere

\footnotetext{
${ }^{23}$ Por exemplo, Leech-Wilkinson argumenta que, no trabalho de artistas como Harnoncourt, Brüggen, Bylsma, Norrington, Hogwood e Kuijken, encontramos a reação modernista tardia contra a complacência materialista e tecnológica, uma volta a um estado original mais primitivo que o mundo moderno havia coberto confortavelmente'; 'Recordings and Histories of Performance Style', em The Cambridge Companion to Recorded Music, 253.
} 
fundamentalmente da que nasceu na Bélgica, Alemanha e Suíça no período entre guerras, quando a Auffuhrungspraxis alcançou uma sólida base acadêmica. ${ }^{24}$

A visão de que "o valor autêntico da Performance Historicamente Informada não é sua reconstrução acadêmica, mas sim um estilo de performance modernisticamente tardio", adotado por Leech-Wilkinson e Richard Taruskin ${ }^{25}$, é para Cook “hoje amplamente aceito” (p. 28), embora isso seja mais verdadeiro em alguns círculos do que em outros. Essa é a visão de muitos músicos ativamente envolvidos com a Performance Historicamente Informada, ou aqueles que organizam, promovem e gravam esse trabalho, para não mencionar os estudiosos que escreveram criticamente sobre o trabalho de Taruskin e outros? ${ }^{26}$ Suspeito que tais argumentos possam ser mais territoriais: priorizando o estudo das gravaçóes acima dos documentos. Isso tem o efeito de não apenas descartar grande parte do trabalho de outros grupos de pesquisa (e muitos outros fora do Reino Unido), mas também negando a possibilidade de diferentes abordagens e estilos daqueles que podem ser notados em gravações iniciais.

A afirmação de Cook de que "como as evidências em questão foram produzidas por especialistas e com base em fontes documentais, o efeito prático foi a performance limitada a ambientes acadêmicos e textos acadêmicos" não é sensata, vinda de um estudioso que escreveu mais do que algumas meras palavras sobre performance ${ }^{27}$ Ele observa com desprezo que, no trabalho de Wallace Berry, “a prática está subordinada à teoria” mas qual performance não é? O que os professores pregam e intérpretes seguem, mesmo em um conservatório, são 'teorias'; a questão é o grau de reflexão crítica. Cook inventa um termo "Performance Analiticamente Informada", o que ele afirma existir principalmente nas universidades e que "é realizada dentro dos contextos de

\footnotetext{
${ }^{24}$ Sobre a história inicial do termo Auffubrungspraxis e a literatura inicial sobre o assunto, como a de Hans Mersmann, Johannes Wolf, Arnold Schering e Robert Haas, publicados entre 1919 e 1931, veja Rudolf Stephan, "Zum Thema historische Auffubrungspraxis ", Jahrbuch des Staatlichen Instituts fur Musikforschung Prenischer Kulturbesitz, 11/1 (1994), 9 - 19.

${ }^{25}$ Daniel Leech-Wilkinson, 'What We Are Doing with Early Music is Genuinely Authentic to such a Small Degree that the Word Loses Most of its Intended Meaning', Early Music, 12 (1984), 13-16 [O que estamos fazendo com a música antiga é genuinamente autêntico em um grau tão pequeno que a palavra perde a maior parte de seu significado pretendido ]; e muitos dos ensaios coletados em Taruskin, Text and Act.

${ }^{26}$ Não menos importante, em John Butt, Playing with History: The Historical Approach to Musical Performance (Cambridge, 2002), 14 - 24; Walls, History, Imagination and the Performance of Music, 1-10; e mais recentemente Nick Wilson, The Art of Re-Enchantment: Making Early Music in the Modern Age (Nova Iorque, 2014), 37 - 53.

${ }^{27}$ Nicholas Cook, 'Bridging the Unbridgeable? Empirical Musicology and Interdisciplinary Performance Studies', em Cook e Richard Pettengill (eds.), Taking it to the Bridge: Music as Performance (Ann Arbor, 2013), 71.
} 
epistemologias acadêmicas, visando a formatação de critérios de avaliação” (p. 97). Isso se assemelha a outro de seus conceitos: "a performance (E)struturalista", mais conhecida como performance modernista - o tipo de performance em termos da qual os escritos de Schenker sobre performance foram lidos - devem ser vistos como um estilo histórico, e não um paradigma da performance em geral, com o qual ela tem sido amplamente ressentida nos círculos teórico-pedagógico da música” (p. 87). Eu não sei o que seria uma performance não-“estruturalista”; todos os artistas, em certo sentido, articulam aspectos estruturais de uma peça, intencionalmente ou não. No capítulo 7, Cook é cético sobre se à “estrutura em larga escala” é o local “mais produtivo para procurar as emergências do significado musical” (p. 246), citando Leech-Wilkinson ao alertar os intérpretes para que desconfiem dos teóricos da música. Mas todo artista precisa tomar decisóes sobre tais estruturas de larga escala a como dinâmicas relativas, tempos, uso de diferentes sons e texturas em pontos estratégicos. Afirmar que o trabalho analítico nunca poderia fornecer frutos, nesses aspectos, parece como uma má vontade ou mesmo um anti-intelectualismo musicológico. Tim Carter escreveu sobre estudantes que pensam que, além de simplesmente "tocar as notas", tudo o que precisamos é de 'sinceridade e reverência'; ${ }^{28}$ esses alunos estariam desprezando o trabalho de Cook e de seus colegas do CHARM da mesma forma com que o próprio trabalho do CHARM deseja que eles ignorem.

Cook escreve: 'A ideia do dever do artista tem tradicionalmente duas versóes; por um lado, dever para com o compositor, por outro, para com à obra (às vezes referido como Werktreue)' (meu itálico) (pág. 13). Oito páginas depois ele segue dizendo que "A Werktreue é quase completamente irrelevante para a grande corrente do pianismo do século XIX, centrada no culto ao virtuosismo e que culminou nas 'guerras de piano' no segundo quarto do século” (p. 21).$^{29}$ Então, o que ele quer dizer com "tradicionalmente”? A abordagem agora denotada pelo termo Werktreue já foi associada

\footnotetext{
${ }^{28}$ Tim Carter, 'It's All in the Notes?', Early Music, 61 (2013), 81-2 à 81 . Para observaçốes mais amplas sobre a indiferença de artistas quanto à musicologia (incluindo trabalhos feministas ou críticas de autonomia que Cook e outros favorecem), consulte George Kennaway, "Historiographically Informed Performance?", Em Vesa Kurkela e Markus Mantere (eds.), Critical Music Historiography: Probing Canons, Ideologies and Institutions (Farnham, 2015), $159-71$.

${ }^{29}$ Essa visão contrasta fortemente com a afirmação simplista de Lydia Goehr de que "o ideal de Werktreue permeou todos os aspectos da prática em e após 1800 com força reguladora total"; Goehr, The Imaginary Museum of Musical Works: An Essay in the Philosophy of Music (Oxford, 1992), 242.
} 
a músicos muito específicos, como Clara Schumann, ${ }^{30}$ Joseph Joachim e, para alguns, Hans von Bulow (mas talvez Texttrene teria sido mais apropriado no último caso). ${ }^{31}$ Mas quando Liszt, sem dúvida uma figura central naquelas 'guerras de piano', escreveu a Richard Pohl em 1853, sobre como uma "batida imperturbável do tempo" em Beethoven leva a uma situação na qual "a letra mata o espirito, atitude à qual nunca subscreverei; no entanto, ilusórios em sua imparcialidade hipócrita, podem ser esses os ataques aos quais sou exposto", ${ }^{32}$ ele também estava reivindicando uma fidelidade ao "espírito" da obra, o que se qualificaria pelo menos como alguma forma de Werktreue.

Em consonância com a obsessiva rejeição da Nova Musicologia da abstração, Lawrence Kramer pediu em 2007 que a performance sugerisse conexões verbais e imaginárias com o mundo. ${ }^{33}$ Cook visa algo semelhante mediante teoria dos tópicos: ele expõe notas de tópicos para a exposição da Piano Sonata K. 332 de Mozart, fornecida por Wye Jamison Allanbrook, e defende os fortes contrastes resultantes entre material-contrastes que Hans-Georg Nageli citou em 1826 para criticar Mozart. ${ }^{34}$ Em 1984, Nikolaus Harnoncourt deixou claro que compartilhava o diagnóstico de Nageli, mas com uma valorização oposta; ${ }^{35}$ Cook cita Harnoncourt em geral sobre uma concepção retórica da música, embora não se refira a Nageli e seus comentários historicamente contextualizadores. A pesquisa subsequente de Cook de oito gravaçóes de K. 332 (desta vez com três em instrumentos de época) é dominada por tópicos, mas com pouco em suas correspondências e relacionamentos. Ele diz: “Em nenhuma dessas gravações há o menor sinal do 'Teatro de rua' de Allanbrook", o que é justo o suficiente, mas em uma versão completamente diferente, essa definição pode ser encontrada na interpretação do forte-pianista norueguês Liv Glaser (de maneira mais fática

\footnotetext{
${ }^{30}$ Veja e.g. Angelika App, 'Die' 'Werktreue' 'bei Clara Schumann', em Peter Ackermann e Herbert Schneider (eds.), Clara Schumann: Komponistin, Interpretin, Unternehmerin, Ikone (Hildesheim, Zurich, e Nova York, 1999), 9 - 18.

${ }^{31}$ Uma investigação abrangente do pensamento histórico sobre tais concepçóes pode ser encontrada na série de palestras de Hermann Danuser, de 1988, 'Werktreue und Texttreue in der musikalischen Interpretation', reimpresso em Sabine Ehrmann Herfort, Ludwig Finscher e Giselher Schubert (orgs.), Europa ische Musikgeschichte, Band 2 (Kassel, 2002), 1115 - 65.

${ }^{32}$ Liszt a Richard Pohl, 5 de novembro de 1853, em Letters of Franz Liszt, i: i: From Paris to Rome: Years of Travel as a Virtuoso, ed. La Mara, trad. Constance Bache (Londres, 1894), $175^{\wedge} 6$.

${ }^{33}$ Lawrence Kramer, Why Classical Music still Matters (Berkeley, 2007), 83. Não é coincidência que Kramer cite Cook anteriormente nesta página.

${ }^{34}$ Hans-Georg Na Geli, Vorlesungen Musik mit Berucksichtigung der Dilettanten (Stuttgart, 1826), 157

${ }^{35}$ Veja Nikolaus Harnoncourt, The Musical Dialogue: Thoughts on Monteverdi, Bach and Mozart, trad. Mary O'Neill (Portland, Oregon, 1989), 86-7.
} 
do que na gravação de Malcolm Bilson, que Cook investiga em detalhes, citando suas visões mais amplas). ${ }^{36}$ Em essência, Cook iguala uma leitura 'tópica' da notação com uma abordagem "retórica" da performance, que ele contrasta com uma abordagem "estruturalista”. A partir disso, ele conclui que “o próprio tecido do estilo clássico é representacional” (p. 109) e, mais tarde, que "a performance retórica se volta às referências e, nesse sentido, é uma prática semiótica” (p. 125). Sua comparação das visões de fortes-pianistas como Malcolm Bilson e Bart van Oort com a ambição de Heinrich Schenker da abolição das "ligaduras de frase” é muito enfática, assim como é a notável e detalhada comparação da gravação de Van Oort do Rondo alla turca de Mozart com uma série de gravaçôes e piano-rolls das primeiras décadas do século XX, lidos em relação às ideias de Schenker e Adolf Kullak.

Meu maior problema com o livro está nas questôes que combinam estilo literário a ideologia. Cook escreve em um estilo bastante frio e impessoal, que sugere um nível de desinteresse estético e uma neutralidade quase-científica, embora isso seja desmentido pela maneira muitas vezes carregada e moralista com que ele estabelece oposiçóes e argumentos. Como mencionado anteriormente, ele evita advogar por uma posição. Da mesma forma, há pouco ou nenhum sentido de identificação pessoal ou empatia com a música e as performances discutidas ao longo do livro. Mas quando participamos da cultura, mesmo casualmente, criamos julgamentos; a exclusão de qualquer indício de tal coisa é o que dá ao livro uma sensação de "acadêmico". ${ }^{37}$ Essa abordagem, também encontrada no trabalho de Stuart Hall, Howard Becker, Tony Bennett, Fred Inglis e outros, retiraos da experiência vivida da cultura, tornando-os envolvidos apenas com amostras de laboratório. Além disso, evitar o julgamento de valor está radicalmente em desacordo com a experiência de qualquer artista que escuta criticamente o próprio trabalho e o modifica de acordo esse julgamento. Isso seria possível sem algum sistema de valorização; como um artista ativo isso me faz sentir profundamente desconfortável ao ler o texto de Cook.

Cook defende que a música é uma prática social, mas desconsidera as abordagens de produção musical que tentam romper com as práticas existentes. Sua definição de social é a de um

\footnotetext{
${ }^{36}$ Wolfgang Amadeus Mozart, Piano Sonatas vol. 4; Liv Glaser, fortepiano; Simax-PSC1148 (1995)

${ }^{37}$ Esse tipo de argumento é apresentado em Terry Eagleton, The Illusions of Postmodernism (Oxford, 1996), p. 93. O sociólogo Simon Stewart apresenta uma consideração relativamente equilibrada dos problemas inerentes quando a sociologia abandona o relativismo e se rende ao mercado, em Sociological Research Online, [Pesquisa Sociológica Online], 18/1 (2013), http://www.socresonline.org.uk/18/1/14.html (acessado em 5 de março de 2016).
} 
empirista ideológico, limitado aos fenômenos que, por dados empíricos, podem ser associados a práticas sociais ou meios particulares; então seria ser antissocial tentar modificar essas associaçôes. ${ }^{38}$ Essa é a própria essência de um posição conservadora, apesar da retórica comunitária que a acompanha. Rejeitando uma função crítica da arte, a posição de Cook para mim exclui a criatividade - pois o que é criar, se não fazer algo novo (mesmo para compositores que não foram, relativamente, inovadores, como Mozart ou Brahms)?” ${ }^{39}$ Em outro lugar, critiquei uma divisão proposta por John Croft: “a pesquisa descreve o mundo; a composição adiciona algo ao mundo”. Isso caracterizaria adequadamente a diferença entre este trabalho de Cook e o de um artista. ${ }^{40}$

Certos performers do mainstream são tratados com especial deferência, colocados em um pedestal mais alto do que estudiosos e compositores, enquanto outras figuras são descartadas. ${ }^{41}$ Performers são vistos como tendo tudo ou nada para aprender com os acadêmicos. Cook e outros criticam duramente esses fenômenos relativamente inofensivos, como o analista defendendo e julgando estratégias específicas de performance, mas eles negligenciam a crítica à cultura do conservatório - mais hierárquica e menos crítica do que a da universidade, às vezes produzindo desespero, medo, insensibilidade a autoridades carismáticas, abuso, bullying e muito mais, e a extensão desses princípios no mundo da performance profissional. Isso aparece apenas uma vez no livro, quando ele cita a pesquisa de Stephen Cottrell sobre instrumentistas e regentes ditadores, se voltando depois para as opiniôes do consultor de administração Yaakov Atik sobre resolução de disputas, que são tomadas praticamente como lei (págs. 269-70).

A falta geral de consideração de Cook pela pedagogia histórica e comparativa da performance é também reveladora. Aprender um instrumento para executar notas musicais frequentemente

\footnotetext{
${ }^{38}$ Para uma crítica marxista sustentada da substituição da musicologia pelas ciências sociais empíricas, no processo de reprodução e reforço das categorias burguesas (e hierarquias de classe), veja as críticas ao trabalho de Sara Thornton, Georgina Born e Simon Frith em Ben Watson, Adorno for Revolutionaries (Londres, 2011), 99 - 148.

${ }^{39}$ Esta posição de Cook foi fortemente criticada por Anne Boissièrre em 'L' Ambivalence d'une approche: Critique ou nihiliste? ', Musicae Scientiae, Fórum de discussão 2 (2001), 29 - 33, em resposta à qual Cook localizou as origens de seu argumento dentro do ataque ao capitalismo e ao consumismo que se desenvolveu em todo o mundo de língua alemã no século XIX (onde estava associado aos valores nostálgicos de um passado rural idealizado) e alimentava principalmente no credo nazista de "sangue e solo"; Cook 'Writing on Music or Axes to Grind', 257.

${ }^{40}$ John Croft, "Composição não é pesquisa" 'Composition is not Research', Tempo, 69/272 (abril de 2015), 6 - 11 at 8, e minha resposta a isso, 'Composition and Performance Can Be, and Often Have Been, Research', Tempo', 70/275 (janeiro de 2016), 60 - 70.

${ }^{41}$ Como testemunhado por sua citação de Wanda Landowska, imagine Rameau subindo de seu túmulo para comentar sobre a performance dela em seu trabalho, e ela o afastar (p. 95).
} 
implica em desenvolver a sofisticação e a sutileza da percepção dessa música. Aqueles que ouvem performances podem ter recebido algum treinamento e a educação musical mais ampla (algumas delas longe do instrumento ou da voz) melhora essa percepção. Isso não está tão distante do domínio da 'apreciação musical', facilitada por gravações e lamentada por Virgil Thomson, a quem Cook tacitamente cita (pp. 309, 365-6). Mas quando a própria noção de um modo educado de ouvir é fortemente questionada pela própria educação, não é de surpreender que professores fiquem com novos alunos apenas demonstrando habilidades auditivas muito elementares. Os professores podem tentar desenvolvê-las ou tomar a opção mais fácil de reorientar a educação musical (que pode, por sua vez, facilitar cortes de financiamento). Pela crescente preponderância desta última solução, eu acredito que toda a escola de pensamento legada por Cook tem alguma responsabilidade.

Este livro é uma espécie de manifesto, a cujas reivindicações eu tentei responder. Analistas mais antigos ou estudiosos da Performance Historicamente Informada não se intimidam em emitir julgamentos estéticos e frequentemente tratam performers - e ouvintes - como pessoas capazes de fazer escolhas, que por sua vez podem ser analisadas e criticadas. Os estudos modernos sobre a performance pós-CHARM se beneficiaram de estudos de uma exploração maior e mais livre, afastando-se de disputas territoriais e argumentos que têm um impacto limitado sobre comunidades mais amplas de artistas ou ouvintes.

\section{REFERENNCIAS}

APP, Angelika. Die 'Werktreue' bei Clara Schumann. In: Peter Ackermann e Herbert Schneider (eds.). Clara Schumann: Komponistin, Interpretin, Unternebmerin, Ikone. Hildesheim, Zürich, e Nova York: Olms, 1999.

BERRY Wallace. Musical Structure and Performance. New Haven: Yale University Press, 1989.

BIASUTTI, Michele; SEDDON, Frederik. Modes of Communication Between Members of a String Quartet. Psychology of Music, 37 (2009) pp. 395-415.

BOISSIÈRE, Anne. L' Ambivalence d'une approche: Critique ou nihiliste?. Musicae Scientiae, Discussion Forum 2 (2001), pp. 29 - 33.

BUTT, John. Playing with History: The Historical Approach to Musical Performance. Cambridge: Cambridge University Press, 2002. 
CARTER, Tim. It's All in the Notes?. Early Music, 61 (2013) pp. 81-92.

CHARM. Style, Performance, and Meaning in Chopin's. Disponível em: $<$ http://www.charm.rhul.ac.uk/projects/p2_3.html>. Accesso em 18 de nov. de 2015.

COOK, Nicholas. Beyond the Score: Music as Performance. Oxford: Oxford University Press, 2013.

- PETTENGILL, Richard. 'The Unbridgeable? Empirical Musicology and Interdisciplinary Performance Studies'. In Nicholas Cook e Richard Pettengill (eds.). Taking it to the Bridge: Music as Performance. Ann Arbor: University of Michigan Press, 2013.

. Writing on Music or Axes to Grind: Road Rage and Musical Community. Musical Education Research, 5/3 (Nov. 2003), 249-261.

. Analysing Musical Multimedia. Oxford: Oxford University Press, 1998.

. The Schenker Project: Culture, Race, and Music Theory in Fin-de-siecle Vienna.

Oxford: Oxford University Press, 2007.

- Writing on Music or Axes to Grind: the timbral, textural and performative qualities of popular music. In: Nicholas Cook. Music, Performance, Meaning: Selected Essays. Londres: Routledge, 2007.

COSTA, Neal Peres Da. Off the Record: Performing Practices in Romantic Piano Playing. Oxford: Oxford University Press, 2012.

COTTRELL, Stephen. The Rise and Rise of Phonomusicology. In: Amanda Bayley. Recorded Music: Performance, Culture and Technology. Cambridge: Cambridge University Press, 2010. . Professional Music-Making in London. Londres: Routledge, 2007.

CROFT, John. Composition is not Research. Tempo, 69/272 (abril de 2015).

CRUTCHFIELD, Will. Vocal Performance in the Nineteenth Century. In: Colin Lawson e Robin Stowell (eds.). The Cambridge History of Musical Performance. Cambridge: Cambridge University Press, 2012.

DANUSER, Hermann. Werktreue und Texttreue in der musikalischen Interpretation. In: Sabine Ehrmann-Herfort, Ludwig Finscher e Giselher Schubert (eds.). Europäische Musikgeschichte, Band 2. Kassel: Metzler, 2002.

DAVIES, Stephen. Musical Works and Performances: A Philosophical Exploration. Oxford: Oxford University Press, 2001.

DAY, Timothy. A Century of Recorded Music: Listening to Musical History. New Haven: Yale University Press, 2000.

DUNSBY, Jonathan. Performing Music: Shared Concerns. Oxford: Oxford University Press, 1995.

EAGLETON, Terry. The Illusions of Postmodernism. Oxford: Oxford University Press, 1996.

EVERIST, Mark. COOK, Nicholas. Analysing Performance and Performing Analysis. In: EVERIST, Mark. COOK, Nicholas (eds.). Rethinking Music. Oxford: Oxford University Press, 1999. 
FABIAN, Dorottya. Bach Performance Practice 1945-1975: A Review of Sound Recordings and Literature. Aldershot: Ashgate, 2003.

The Meaning of Authenticity and the Early Music MovementçA Historical Review. International Review of the Aesthetics and Sociology of Music, 32/2 (Dec. 2001).

. Is Diversity in Musical Performance truly in Decline?: The Evidence of Sound Recordings. Context: A Journal of Music Research, 31 (2006).

FROTSCHER, Gotthold. Auffübrungspraxis alter Musik. Wilhelmshaven e Amsterdam: Heinrichschofen, 1963.

GELI, Hans-Georg Na. Vorlesungen Musik mit Berücksichtigung der Dilettanten. Stuttgart: Cotta, 1826.

GOEHR, Lydia. The Imaginary Museum of Musical Works: An Essay in the Philosophy of Music. Oxford: Oxford University Press, 1992.

GRASSL, Markus. KAPP, Reinhard. Kapp (eds.), Die Lebre von der musikalischen Auffübrung in der Wiener Schule. Vienna: Böhlau, 2002.

HARNONCOURT. Nikolaus. The Musical Dialogue: Thoughts on Monteverdi, Bach and Mozart. Tradução de Mary O’Neill. Portland: Amadeus Press, 1989.

HAYNES, Bruce. The End of Early Music: A Period Performer's History of Music. Oxford: Oxford University Press, 2007.

HILL, Robert. Arbeitsgemeinschaft für musikalische Werkpraxis. In: Bryan Gilliam (ed.), Music and Performance during the Weimar Republic. Cambridge: Cambridge University Press, 1994.

JOHNSON, Peter. COOK, Nicholas. ZENDER, Hans. Theory into Practice: Composition, Performance and the Listening Experience. Leuven: Leuven University Press, 1999.

KENNAWAY, George. Historiographically Informed Performance?. In: Vesa Kurkela e Markus Mantere (eds.). Critical Music Historiography: Probing Canons, Ideologies and Institutions. Farnham: Routledge, 2015.

KENYON, Nicholas. Authenticity and Early Music. Oxford: Oxford University Press, 1988.

KIVY, Peter. Authenticities: Philosophical Reflections on Musical Performance. Ithaca: Cornell University Press, 1995.

KLAUS, Heinz Metzger. RIEHN. (eds.), Rudolf Kolisch: Zur Theorie der Auffuhrung. Munich: Aulage, 1983.

KRAMER, Lawrence. Why Classical Music still Matters. Berkeley: University of California Press, 2007.

KRONES, Harmut. 175 Jahre Aufführungspraxis Alter Musik in Wien. in Krones (ed.), Alte Musik und Musikpädagogik. Viena: Böhlau, 1997.

MILSOM, David. Theory and Practice in Late Nineteenth-Century Violin Performance. Aldershot: Ashgate, 2003.

PACE, Ian. Composition and Performance Can Be, and Often Have Been, Research. Tempo, 
70/275 (janeiro de 2016).

Notation, Time and the Performer's Relationship to the Score in Contemporary Music. In: Darla Crispin (ed.), Unfolding Time: Studies in Temporality in Twentieth-Century Music. Leuven: Leuven University Press, 2009.

PHILIP, Robert. Early Recording and Musical Style: Changing Tastes in Instrumental Performance, 1900-1950. Cambridge: Cambridge University Press, 1992.

RINK, John. The State of Play in Performance Studies. In: Jane W. Davidson. The music Practitioner: Research for the Music Performer Teacher and Listener. Aldershot: Ashgate, 2004.

- The Practice of Performance: Studies in Musical Interpretation. Cambridge: Cambridge University Press, 1995.

STEPHAN, Rudolf. Zum Thema historische Auffübrungspraxis, Jahrbuch des Staatlichen Instituts für Musikforschung Preuischer Kulturbesitz, 11/1 (1994), 9 - 19.

STEWART, Simon. Evaluating Culture: Sociology, Aesthetics and Policy, Sociological Research Online, 18/1 (2013), disponível em <www.socresonline.org.uk/18/1/14.html> (acessado 5 Mar. 2016 ).

TARUSKIN, Richard. Text and Act: Essays on Music and Performance. Oxford: Oxford University Press, 1995.

THORNTON, Sara. BORN, Georgina. FRIT, Simon. In Ben Watson. Adorno for Revolutionaries. Londres: Unkant, 2011.

WALLS, Peter. History, Imagination, and the Performance of Music. Woodbridge and Rochester: Boydell, 2003.

WILKINSON, Daniel Leech. Recordings and Histories of Performance Style. In: The Cambridge Companion to Recorded Music. Cambridge: Cambridge University Press.

Performances (Londres, 2009), disponível em
<www.charm.rhul.ac.uk/studies/chapters/intro.html> (acessado em 10 de novembro de 2015).

WILSON, Nick. The Art of Re-enchantment: Making Early Music in the Modern Age. New York: Oxford University Press, 2014.

\section{SOBRE OS AUTORES}

Ian Pace é um pianista de reputação estabelecida, especializado nos mais distantes pontos do modernismo musical e do virtuosismo transcendental, além de escritor e musicólogo com foco em questôes de performance, música e sociedade e vanguarda. Ele nasceu em Hartlepool, estudou na Escola de Música de Chetham, The Queen's College, Oxford e, como Fulbright Scholar, na Juilliard School, em Nova York. Seu professor principal, e uma grande influência em seu trabalho, 
PACE, Ian. O novo estado da arte dos estudos em performance. Tradução de: Vitória Liz P. Louveira e William Teixeira. Revista Vórtex,

foi o pianista húngaro György Sándor, um aluno de Bartók. Atualmente é professor da City University London. Email: ianpace1@city.ac.uk

Vitória Louveira é acadêmica do Curso de Música - Licenciatura da UFMS e ministra aulas de violão na Escola de Música da UFMS. Atualmente é bolsista de iniciação científica do PIBIC-CNPq. ORCID: https://orcid.org/00000002-7229-3100. E-mail: vitorializparaguassu@gmail.com

William Teixeira é Doutor em Música pela USP e Professor Adjunto da UFMS. Como violoncelista já atuou como solista frente a grupos como a Orquestra Sinfônica da UNICAMP, Orquestra Sinfônica de Rio Claro, Orquestra de Câmara da USP e a USP-Filarmônica. ORCID: https://orcid.org/0000-0002-6622-378X. E-mail: william.teixeira@ufms.br 